\title{
Relating thermohaline simulation of salt dissolution to land collapse at a Transylvanian salt diapir, Romania
}

\author{
Eric Zechner ${ }^{1}$, Horst Dresmann ${ }^{1}$, Marius Mocuţa², Alex Danchiv², Peter Huggenberger ${ }^{1}$, Stefan \\ Scheidler ${ }^{1}$, Stefan Wiesmeier ${ }^{1}$, Iulian Popa ${ }^{2}$, and Alexandru Zlibut $^{2}$ \\ ${ }^{1}$ University of Basel, Department of Environmental Sciences, Basel, Switzerland (eric.zechner@unibas.ch) \\ ${ }^{2}$ University of Bucharest, Department of Geological Engineering, Bucharest, Romania
}

The presented study estimates salt dissolution caused by groundwater around a salt diapir in the Transylvanian Basin, which is facing land-collapse hazards related to historic salt mining activities. Because the amount of salt dissolution is controlled by the concentration gradients and fluxes near vulnerable areas of the salt dome, specific attention has been given to hydrogeological boundary conditions. They include the hydraulic role of possible more permeable fault zones along the salt dome, and the potential access to the salt diapir of over-pressurized subsaturated groundwater within regional scale sandstone layers. A structural three-dimensional (3D) model of the salt diapir, the adjacent basin sediments, and the mining galleries was developed based on existing maps, borehole data, own field observations, and geological publications of the Transylvanian Basin. The salt dissolution potential was simulated with $2 \mathrm{D}$ vertical thermohaline flow and transport model scenarios along the southeastern flank of the diapir. Results showed that the following factors increase the salt dissolution capacity along the upper $180 \mathrm{~m}$ of the diapir: (1) the presence of more permeable Quaternary alluvial sediments in connection with a fault zone of higher permeability along the diapir, and (2) the presence of more permeable sandstone units within the Miocene sediments in the east of the diapir, which provide freshwater access to the upper parts of the diapir. Thermohaline simulation with viscosity variation of the fluid, instead of a constant viscosity, influences the resulting salt fluxes by up to $50 \%$ within studied temperature ranges of 10 to $60^{\circ} \mathrm{C}$ in the model domain. The range of theoretical dissolution rates along the upper $180 \mathrm{~m}$ of the diapir supports the hypothesis that cavern collapse is more likely to occur where cavern side walls have already been mined to almost no remaining side walls of rock salt, which is the case in the southeastern part of the diapir. A past land collapse from 2010, which formed a 70-90 m wide saline lake, has occurred in this area southeast of the diapir appearing to be the more vulnerable to land collapse.

Zechner, E., Dresmann, H., Mocuţa, M., Danchiv, A., Huggenberger, P., Scheidler, S., Wiesmeier, S., Popa, I., Zlibut, A. (2019): Salt dissolution potential estimated from two-dimensional vertical thermohaline flow and transport modeling along a Transylvanian salt diapir, Romania, Hydrogeol. J., 27, 1245-1256, https://doi.org/10.1007/s10040-018-1912-1. 